\title{
SUSTAINABLE FACTORS IN THE HUMAN ASSETS OF DANA HOTEL AS A HERITAGE HOTEL IN SOLO, INDONESIA
}

\author{
Wahyuniwati Wahyudi ${ }^{*}$, Endo W. Kartika ${ }^{2}$, Sia Tjun Han $^{3}$ \\ ${ }^{123}$ Hotel Management Program, Faculty of Economics, Petra Christian University, Surabaya 60236, Indonesia \\ *Corresponding author. Email: wahyuniwati@petra.ac.id
}

\begin{abstract}
This research aims to study what sustainable factors of Dana Hotel in the human assets; and also find out what the status of Dana Hotel, using VRIN analysis (Value, Rarity, Imperfect Imitability, and Non-Substitutability) from Natural Language Data of observation and in-depth interviews in a descriptive qualitative study. In results, in order to achieve sustainability, Dana Hotel has valuable, rare, imperfectly imitable, and non-substitutable factors in the human assets. As the human assets are valuable, rare, imperfectly imitable, and non-substitutable, the status of Dana Hotel is sustainable in the context of human resources. It is concluded that following the success of Dana Hotel, organizations that have those factors or even more, tend to have big opportunities to survive.
\end{abstract}

Keywords: Strategic management, sustainability, hospitality business, heritage hotel, resource-based view.

\section{Introduction}

A royal city of Solo (formally known as Surakarta), the very well-known city in Indonesia, is particularly proud of its Javanese culture and traditions with exciting old markets, busy street life, ancient buildings, and art performances such as Solonese dance, Wayang puppetry, and hand-crafted Batik Solo. The other cultural attractions are the two Keratons or Palaces, Keraton Kasunanan, Palace of the Pakubuwono Kings, a combination of traditional Javanese and Classical European styles with Panggung Songgobuwono, and the other palace is Puro Mangkunegara for the Princess. Moreover, an easy access to the city for domestic and international tourists gives significant impacts to Solo as a tourism city.

Due to such an increase of tourism arrivals, the hotel industry will need to accommodate the demand by providing more properties. However, before 1952, there is no hotel that is representative enough to accommodate tourists who came to Solo. Mangkunegaran, the founder of Dana foundation initiatively builds the first modern hotel at that time. A fifty year old building of Dana Hotel, which is formerly owned by Prince Poerbonegoro, a son of the late king Pakubuwono $\mathrm{X}$, is renovated to be an antique hotel with modern facilities. The hotel is named Dana Hotel, and is opened to public on May 25, 1953.

In fact, according to the Indonesian Hotel and Restaurant Association (PHRI), based on the statistic data from PHRI from 2010 until 2013, the percentage of the hotel growth is $79 \%$, and the room growth is $190 \%$. In contrast, the increment of tourist arrivals is only $36 \%$. These data show how hotel business is getting more competitive. This case might be a threat for Dana Hotel that has been in Solo surviving since 1953 until now. Since Dana Hotel successfully shows the good performance until now, it brings a curiosity in finding out what makes Dana Hotel survive. A firm's ability to survive and prosper depends on choosing and implementing a good strategy (Barney, 1991), so the survival of Dana Hotel is very important to study. In addition, conducting a study concerning Solo grabs more people's attention in mind also, since currently, popularity of Solo as the birthplace of the current president of Indonesia, Joko Widodo, is fast-rising. He led as mayor of Solo from 2005 to 2012. Under Joko Widodo's control, the city has experienced an obvious improvement. He rebranded and promoted Solo as "The Spirit of Java," a Javanese culture and heritage center, batik capital, and tourist friendly city.

Corresponding to surviving in the hotel business competition, if the firm has a resource or capability which is valuable, rare, costly to imitate, and nonsubstitutable; exploiting it will generate a sustained competitive advantage (Barney, 1991). This research aims to focus on what the sustainable factors of Dana Hotel to survive in human assets are; and also find out what the status of Dana Hotel is, using VRIN analysis framework.

A firm's ability to survive and prosper depends on choosing and implementing a good strategy. The strategic management process is a sequential set of analyses and choices that can increase the likelihood that a firm will choose a good strategy that generates competitive advantages. Internal analysis helps a firm understand which of its resources and capabilities are 
likely to be sources of competitive advantage and which are less likely to be sources of such advantages. In general, a firm has a competitive advantage when it is able to create more economic value than rival firms. A firm's competitive advantage can be temporary (a very short period of time) or sustained (much longer time) (Barney, 1991).

Resource-based view (RBV) is a model of firm performance that focuses on the resources and capabilities controlled by a firm as sources of competitive advantage. A firm's resources and capabilities can be classified into four broad categories: financial resources, physical resources, human resources, and organizational resources. Armed with the RBV, it is possible to develop a set of tools for analyzing all the different resources and capabilities a firm might possess and the potential of each of these to generate competitive advantages. The primary tool for accomplishing this internal analysis is called the VRIO framework for four questions: the question of Value, Rarity, Imperfect Imitability, and non-substitutability or sometimes replaced by Organization (Barney, 1991).

The question of value is: "Do resources and capabilities enable a firm to exploit an external opportunity or neutralize an external threat?" If a firm answers this question with a "yes", then its resources and capabilities are valuable. They are only valuable to the extent that they enable a firm to enhance its competitive position. Only when a resource is not controlled by numerous other firms is it likely to be a source of competitive advantage. These observations lead to the question of rarity: "How many competing firms already possess particular valuable resources and capabilities? If a firm's valuable resources and capabilities are absolutely unique among a set of current and potential competitors, they can generate a competitive advantage. In general, as long as the number of firms that possess a particular valuable resource or capability is less than the number of firms needed to generate perfect competition dynamics in an industry, that resource can be considered rare and a potential source of competitive advantage (Barney, 1991).

Valuable and rare organizational resources, however, can be sources of sustained competitive advantage only if firms that do not possess them face a cost disadvantage in obtaining or developing them, compared to firms that already possess them. These kinds of resources are imperfectly imitable. These observations lead to the question of imitability: "Do firms without a resource or capability face a cost disadvantage in obtaining or developing it compared to firms that already possess it?" Competing firms may face an important cost disadvantage in dupli- cating a successful firm's valuable resources. If this is the case, this one innovative firm may gain a sustained competitive advantage (Barney, 1991).

In general, imitation occurs in one of two ways: direct duplication or substitution. If the resources have no substitutes, or of the cost of acquiring these substitutes are greater than the cost of obtaining the original resources, then competitive advantages can be sustained. Further, unique historical consequences the causally ambiguous relationship between firm resources and capabilities and competitive advantage can give a firm a sustained competitive advantage. However, it is not always the case that managers in a particular firm will fully understand the relationship between the resources and capabilities they control and competitive advantage. This lack of understanding could be a part of the day-to-day experience of managers in a firm, that these managers are unaware of them.

Organizational resources and capabilities such as teamwork among top managers, organizational culture, relationships among other employees, and relationships with customers and suppliers may be almost "invisible" to managers in a firm. If managers in firms that have such capabilities do not understand their relationship to competitive advantage, managers in other firms face significant challenges in understanding which resources they should imitate. Managers may have multiple hypotheses about which resources and capabilities enable their firm to gain a competitive advantage, but they may be unable to evaluate which of these resources and capabilities, alone or in combination, actually create the competitive advantage. When the resources and capabilities that generate competitive advantage are complex networks of relationships between individuals, groups, and technology, imitation can be costly. Whenever the sources of competitive advantage are widely diffused across people, locations, and processes in a firm, those sources will be costly to imitate, for example, knowledge about a firm's products, processes, customers, and so on widely. Competitors will have difficulty imitating that knowledge, and it can be a source of sustained competitive advantage.

A firm's resources and capabilities may be costly to imitate is that they may be socially complex phenomena including the interpersonal relations among managers in a firm, a firm's culture, and a firm's reputation among suppliers and customers, beyond the ability of firms to systematically manage and influence. When competitive advantages are based on such complex social phenomena, the ability of other firms to imitate these resources and capabilities, either 
through direct duplication or substitution, is significantly constrained (Barney, 1991).

\section{Research Method}

This study is a qualitative research, since the writer collected the data from the real world setting with no control of the phenomenon (Golafshani, 2003) which is that Dana Hotel has successfully survived in the tight hotel business competition in Solo since 1953. Furthermore, a case study is an empirical inquiry that investigates contemporary phenomena within its real-life context, especially a single case study is appropriate when the case is special (in relation to established theory), unique, or has something special to reveal (Rowley, 2002). This study is a single case study, in which the study investigates and describes contemporary phenomena in the real life context as the writer describes what is behind Dana Hotel that makes the hotel survive. Dana Hotel is unique as the hotel has diversity from other hotels as maintaining the old Javanese traditions and having good aura for wedding as the close relationship with the Indonesian Empire Family. These characteristics and uniqueness of Dana Hotel are hardly to find in other hotels. And then, the data in this study is analyzed using VRIN framework analysis focusing on the human assets of the hotel.

The writer does in-depth interviews with the managers of the hotel with the marketing manager of Dana Hotel named Harwati Sulistyaningsih who has been working since 1997; Human Resource Manager, named Dewa Putu Sudharta, who has been working since 1998; and the Head of Front Office Department, named Karyati, who has been working since 2009. Indepth interviews are used to get detail information regarding sustainable factors in the human assets including short-term and long-term missions in the context of human assets and how to achieve; management function of controlling by the managers; culture in the workplace; situation in the working environment; teamwork; relationships between employees, with customers, suppliers, and public; and work motivation of the employees.

This study uses Grounded Analysis Approach in analyzing the interview transcript. Grounded theory involves the discovery of theory from data (Glaser \& Strauss, 1967). In qualitative researches, validity is related to whether the findings of the study are true or certain. "True" means that the findings accurately reflect the real situation. "Certain" means that there are no good grounds for doubting the results in which that the weight of evidence supports the conclusion. This study uses data triangulation, in which the writer compared the interview data from the three informants.

\section{Results and Discussions}

\section{Value of Human Resource Assets}

First of all, Dana Hotel has the values of its human resource assets. In the context of customer service, Dana Hotel maintains the high effectiveness of the number of the employees without reducing the quality of service. In this case, Dana Hotel does not need to have a lot of employees to handle all jobs. All employees at Dana Hotel have enough background knowledge of the jobs from different departments, so that if one of the departments needs a hand or a help from the others, the employees from different departments can directly handle the work without difficulties. All employees get used to help each other as they can do multitasking works, and they have a high level of willingness to help their colleagues while needed.

Multitasking is regarded as the simultaneous engagement of two or more tasks (Buser \& Peter, 2011). Although multitasking process leads to the questions of the effects in doing multitasking including the productivity, the organization proves that they still can maintain the high qualified service since they only have 65 employees in total, including 16 employees for handling service for 48 guest rooms. It is shown that the number of employees for service seems to need more; however, the organization still maintains the value that there is no change in the quality of the service. As well, there is no change in the productivity by maximizing the effectiveness of working with the limited numbers of the employees.

Proposition 1: In order to achieve sustainability in hospitality business, organizations seek to have employees that are able to handle contingent tasks in one time by switching from one task to another task.

Besides, communication and relationship between the employees stay very strong for a long time. There is a high level of the feeling of togetherness, in which every employee has the same idea of becoming a family-like team. As a family team, every employee has his or her own personal calling to help each other whenever they are needed without any hard feeling or burdens. According to Scarnati in the research entitled "Successful Teamwork: A Case Study", Tarricone and Luca (2002) define teamwork as a cooperative process that allows ordinary people to achieve extraordinary results. The employees have developed the effective and mutual relationships between them. 
Proposition 2: In order to achieve sustainability in hospitality business, organizations seek to have cooperative teams which are shown in the high level of togetherness that employees have.

The managers at Dana Hotel have been working for many years, and then they know the process that Dana Hotel has been through until now. The Human Resource Manager has been working for Dana Hotel since 1998. The Sales and Marketing Manager has been working since 1997. The Head of Front Office Department has been working since 2009. This condition has a very high value of high working experience for the managers. The managers have completely understood what Dana Hotel has been facing for years internally and externally. There are many factors that cause turnover in an organization, for example dissatisfaction, a poor relationship, a lack of proper training and development. Dana Hotel, in this case, proves of being an organization that can maintain the spirit and willingness of the employees to stay.

Proposition 3: In order to achieve sustainability in hospitality business, organizations seek to have loyal employees that unwilling to leave their jobs for any other jobs offered elsewhere.

Moreover, Dana Hotel builds a good relationship with the society in Solo. One of the examples is that Dana Hotel conducts many social activities such as donation in Ramadan month for hundreds of orphans nearby. This is in line with the concept of sustainability which is to provide benefits for current generation, without neglecting the effects that it would bring to future society. The issues of sustainability concern with the community development especially giving benefit to the society (Zamzuri, Awang, \& Samdin, 2011).

Proposition 4: In order to achieve sustainability in hospitality business, organizations develop the relationship with the society by giving benefits to meet the needs of care for others who really need.

Further, the relationship between Dana Hotel and other hotels are very good. The employees at Dana Hotel have the same idea to see the other hotels as co-workers or partners, not adversaries, even in reality, the other hotels are competitors in grabbing the customers. Since the relationship between Dana Hotel and the other hotels are very good, Dana Hotel gets benefits of exchanging important information, such as information of what events are conducted recently in Solo, whether there is a certain event in
Solo, or whether there are groups of Government organizations coming to Solo, and many others. By continuously doing this, Dana Hotel builds a good relationship with the other hotels. This finding is in line with the idea that Ingram and Roberts (2000) claim that friendship among competing managers leads to improved collaboration and information sharing. Cooperative relationships are built upon a mutual interest to support each other and interact without restraints in the same business network (Kock, Bengtsson, \& Slotte-Kock, 2003).

Proposition 5: In order to achieve sustainability in hospitality business, organizations seek to have a good relationship with the competitors.

All employees create a comfortable and friendly working environment in which it is supported by some internal activities attended by the employees, for example employees' refreshing activity once a year, gatherings, and Saturday Sport day doing Aerobics together, and meal or snack time together. Every Friday the employees also have an activity of Friday cleaning, as all employees from all departments have an activity of helping the gardeners to keep the hotel clean and to maintain the natural beauty of the plants and the gardens at Dana Hotel. These ideas are in line with the theory that an effective workplace is an environment where results can be achieved as expected by management, because the workplace environment is the most critical factor in keeping an employee satisfied in today's business world (Tarricone \& Luca, 2002). The physical environment that directly affects the human sense and interpersonal interactions is supported by the activities conducted to build a strong personal relationship between the employees such as gathering and together in helping the gardeners in maintaining the beauty and cleanness of the hotel area. These simple but fun activities successfully create such an enjoyable workplace for the employees. The employees get both physically clean working environment and good interpersonal interactions among them, in results; the productivity of the employees is increasing with such a happy working place.

Proposition 6: In order to achieve sustainability in hospitality business, organizations seek to have an effective workplace in which employees have very good performance.

\section{Rarity of Human Resource Assets}

For the rarity of the Human Resource Assets, Dana Hotel has 24 hours service with zero complaint from the customers. In this case, Dana Hotel 
maintains the very high qualified service that always meets the customers' expectations. The numbers of the employees at Dana Hotel are not big, but with a big hotel area at Dana Hotel, all employees have capabilities to cover and handle the jobs very well in order not to disappoint the customers. Based on the theory, internal marketing comes down to delivering service quality in a way that customer is satisfied. In order for a hotel to succeed in delivering service quality it has to have motivated employees who know what they are selling. The goal of internal marketing is to attain the best possible professional skills available (Maarit, 2011).

Proposition 7: In order to achieve sustainability in hospitality business, organizations seek to apply the internal marketing of the hotel very well.

Moreover, Dana Hotel has a solid team. This is very rare that not all hotels have a solidity team as Dana Hotel. Since employees at a hotel are required to work as a team, not individually, all employees from different departments are meant to be connected to each other in order to help each other, to cover all the works. It is believed that the use of teams is an effective approach to achieving organizational goals, especially in solving problems and creating new initiatives that can enhance productivity. The use of teams in organizations is increasing because work carried out in teams is often more efficient and effective than work performed by individuals (Budijanto, 2013).

Proposition 8: In order to achieve sustainability in hospitality business, organizations seek to have a solid team that is connected to each other in order to help each other.

Furthermore, the number of employee turnover is very small, since the employees have been working at Dana Hotel in a long period of time. This rarely happens. Naturally, people want diversities in his/her everyday life; seeks for new and challenging jobs and good working environment in job place. Every organization wished to have high productivity, fewer turnovers and to be profitable. Managing turnover successfully is a must to achieve goals (Shamsuzzoha $\&$ Shumon, 2007).

Proposition 9: In order to achieve sustainability in hospitality business, organizations maintain the talented employees.

In addition, the other rarity that Dana Hotel has is that Dana Hotel and people nearby have a strong relationship. Dana Hotel has built a bridge between
Dana Hotel and the people living at the same area of the hotel. This is in line with the theory that sustainable developments should strengthen the local economy and owners should demonstrate a commitment to addressing the community concerns (Albert, 2010). The organization has a strong relationship with the people nearby. This is because the organization commits to keep demonstrating social activities for community concerns. No rejections or conflicts happen between the organization and the community since the beginning.

Proposition 10: In order to achieve sustainability in hospitality business, organizations seek to achieve a social justice, in which there is no involvement of negative repercussions on the environment and society.

As well, Dana Hotel has a good relationship with the other hotels. Dana Hotel sees other hotels as partners, not opponent or even obstacles. The good relationship between Dana Hotel and other hotels keeps bringing positivity. Cooperative relationships are built upon a mutual interest to support each other and interact without restraints. These relationships are built on a distribution of activities and resources among embedded in the same business network (Kock et al., 2003). Both sides take advantage on each other, but in this case, since they are in the same business network, they can fulfill the lack of resources, so that they need to cooperate, even in reality, the status between them is competitors. This cooperative relationship spontaneously happens since they both have the same idea to support each other without any restraints.

Proposition 11: In order to achieve sustainability in hospitality business, organizations seek to have a cooperative relationship with the competitors.

Further, Dana Hotel is a workplace with a feellike-home environment. That makes the employees do not want to move to another company. The employees see Dana Hotel as a home to happily work at as the employees see each other as a family to gladly work with. In general, the research by Greenberg, Sikora, Grunberg, and Moore (2012), supports the idea that employees who believe they are members of teams that perform at high levels of effectiveness are more positive about organizations that provide opportunities to feel a sense of accomplishment and to be a part of group that is respected by other employees, supervisors, and top management. This leads to the hypothesis in which the employees who report the highest levels of effective- 
ness for their teams will be the more committed to their organization and less likely to report an intention to leave (Greenberg et al., 2012).

Proposition 12: In order to achieve sustainability in hospitality business, organizations seek to create a feel-like-home workplace for employees, so that the employees do not have an idea to move to another organization.

\section{Imperfect Imitability of Human Assets}

In the context of the service, there is a condition of social complexity as imperfect imitability of human assets that Dana Hotel serves the customers by creating a feel-like-home environment. The employees at Dana Hotel know very well what is needed to make the customers feel convenient staying at the hotel, so that the customers will not feel like they go far from home and find another "home" at Dana Hotel. This kind of feeling that the customers have at Dana Hotel is very difficult to be imitated by other hotels as the other hotels might duplicate the service. It will not be the same because the other hotels do not have the same employees as Dana Hotel who creates such environment. A hotel that has high reputation because of quality can sell its service with premium price (Rumambi \& Djati, 2007). The room rate of Dana Hotel is usually stable, never dropped or under the minimum standard of room rate. It shows that if the organization has a brand that is already recognized by the people, the management of the organization will be brave enough to stabilize or even increase the room price. As well, if the organization has a good reputation, the organization will also grab a good selling with the fulfillment of the organization's promises to the customers.

Proposition 13: In order to achieve sustainability in hospitality business, organizations maintain a good reputation of giving a service that can create convenience for customers.

Moreover, there is a social complexity that the employees have a deep connection in both interpersonal and intrapersonal relationship. The interpersonal relationship is that a relation between individuals at Dana Hotel. Intrapersonal relationship is the ability of every individual to communicate with others and to build a relationship, including the politeness, language, the way to speak, and choices of words. The combination of good interpersonal and intrapersonal relationship between employees can create a strong bind between them. This is in line with the theory that collaboration and interaction among team members are vital because the success of the organization relies upon the ability of team members to collaborate and interact effectively and efficiently (Budijanto, 2013).

Proposition 14: In order to achieve sustainability in hospitality business, organizations enhance a conducive working environment for employees.

In addition, since the number of turnover at Dana Hotel is very small, Dana Hotel has high level of day-to-day experienced managers and employees. This happens also because the employees work for Dana Hotel for quite a long time and learn a lot for their everyday experiences. This situation also strengthens the management of Dana Hotel, since Dana Hotel has many loyal employees. This is in line with the theory that it is crucial to maintain a constant workforce particularly for the skilled ones in an organization to reduce turnover for the betterment of the organization (Shamsuzzoha \& Shumon, 2007).

Proposition 15: In order to achieve sustainability in hospitality business, organizations maintain both productivity and skilled employees.

Furthermore, there is another social complexity and causal ambiguity that Dana Hotel has in which people who live nearby the location of Dana Hotel gladly help the employees of Dana Hotel. This usually happens when there are big events, for example wedding ceremonies, the people help Dana Hotel for the parking matters in front of the hotel or the help of the permission to the neighbors nearby if there is loud sound coming from Dana Hotel during the wedding ceremonies. Based on the theory, all the activities of public relations have a purpose to create 'good image' in the society. The image of Public Relations created to affect people's perception toward an organization or institution and can strongly influence public behavior in an honorable way. The responds from the public linked will be in the form of respect, good impression and favors toward an organization or institution that is represented by public relations (Noffytasari, 2010).

Proposition 16: In order to achieve sustainability in hospitality business, organizations maintain a good image and reputation in publics.

In addition, there is a complex network and causal ambiguity between Dana Hotel and other hotels since they become a big network as partners in helping each others in the tight business competition in Solo. Normally, they are competitors, but in this case, they build such a relationship that can give them benefits in getting customers by sharing information 
or giving guests to other hotels when Dana Hotel gets customers more than the rooms available. This phenomenon is in line with the theory that the social relationships between the business professionals will be of importance for doing successful business. As Uzzi (1997) in the research by Soren Kock, Maria Bengtsson, and Susanna Slotte-Kock entitled "To Compete or Cooperate: A Strategic Dilemma" has pointed out will these kind of strong ties provide new trustworthy information and have a great impact on problem-solving, by creating mutual trust and understanding (Kock et al., 2003).

Proposition 17: In order to achieve sustainability in hospitality business, organizations seek to create social relationships with competitors.

As well, another social complexity is that the employees at Dana Hotel see each other as a family, not only co-workers. This condition is still under professional acts between the employees, so that the employees still maintain the high level of professionalism in working. They create a "home" working environment by treating each other as family to make the workplace conducive and healthy. This is in line with the theory that teamwork integrates thinking, feeling, and action between team members to accomplish work in achieving performance goals. Teamwork is recognized as influential to organizational success (Budijanto, 2013).

Proposition 18: In order to achieve sustainability in hospitality business, organizations seek to create a team with extraordinary results in enjoyable working environment, but still maintain the value of professionalism.

\section{Non-Substitutability of Human Assets}

In the context of substitutability of the human assets of Dana Hotel, the service at Dana Hotel is delivered with a touch of traditional Javanese culture, so that the customers will get remarkable sensation and become retentive guests. Since Solo is well known with the strong Javanese culture and tradition, Dana Hotel wants to introduce that culture in real such as direct touch of showing politeness through the actions and language use that Javanese is well known about. One of the examples is that for the room service at Dana Hotel, the employees take off their shoes before they enter the guest rooms to serve food ordered by the guests to be delivered in rooms. In Javanese culture, there is a tradition to take off shoes or sandals before entering someone's room or house as a polite act. The findings are in line with the theory that service quality improvement becomes the most critical issue in the service industry since it can improve the productivity, decrease the cost, build customer satisfaction, and increase profits to firm. The continual improvement of service quality is essential for the competitive advantage of a service business. When customers perceive higher service revitalization, they turn a loyal customer to specific service provider (Akbar, Som, Wadood, \& Alzaidiyeen, 2010).

Proposition 19: In order to achieve sustainability in hospitality business, organizations seek to create remarkable sensations in the service.

Organizations need to know how to acquire and to treat employees wisely as each individual is ultimately responsible for achieving organization's goals (Budijanto, 2013). Dana Hotel is able to maintain the team that the organization has at this moment. The team is very valuable to the organization, since the team shows their good working performance. As people are the most important resources who have the potential to contribute the organizational performance, the organization has already taken the right step to maintain the team. Each individual of the team has his/her uniqueness with styles, talents, personality, beliefs, and values, but in this case, all the differences that the individuals have in the team can come together and support each other in the day-to-day work processes and interactions in order to achieve organization's goals.

Proposition 20: In order to achieve sustainability in hospitality business, organizations know exactly how to treat employees wisely.

Moreover, the loyal employees that Dana Hotel has now are very difficult to find a substitute. Since there is a low number of an employee turnover, the employees at Dana Hotel have a high level of loyalty in working. The employees have been working for Dana Hotel in a very long period of time and do not want to move to another company or to resign from their job. Dana Hotel is very fortunate to have such employees that give their full dedication in working. Turnover directly affects the production and productivity. It causes a replacement which is costly and time-consuming. So many formalities have to maintain to replace a person. The newer one takes time to be easy with the new system. After the replacement, the co-worker has to spend time from their task to help the new worker (Shamsuzzoha \& Shumon, 2007).

Proposition 21: In order to achieve sustainability in hospitality business, organizations maintain not to replace a person in a team. 
As well, the level of solidity between Dana Hotel and people who live nearby the location of Dana Hotel may change if Dana Hotel or employees of Dana Hotel are replaced or substituted. Dana Hotel is already familiar to the people nearby and has a strong relationship built since a long time ago, then this kind of solidity is very difficult to find a substitute. A business should explicitly state not to harm the local population. Community partnerships can be successful if addressing a wide variety of community concerns. The hotels demonstrate a commitment to the community by donating food to the local 'Hunger Network' (Albert, 2010). The organization addresses the issues of poverty and nutrient problems that the orphans face, and then the organization has a commitment to donate food. In results, there is long-term links with the community. There is no harm for the local population, although there are many big events that the organization conducts, such as meetings and wedding ceremonies. The long-term links make people nearby give a high level of respect.

Proposition 22: In order to achieve sustainability in hospitality business, organizations seek to create a partnership with the people nearby with a wide variety of community concerns.

In addition, if there is a substitute of the employees at Dana Hotel, there will also be a change in the relationship between Dana Hotel and the other hotels. The relationship between Dana Hotel and the other hotels are created and built by the employees at this moment so far, then it is very difficult to maintain this relationship if different persons handle it. The employees of Dana Hotel understand exactly how to keep the relationship and make it last long. This is in line with the theory that firms, which had the hardest competition amongst them, also had the greatest return on their manager's long-lasting trustworthy relationships to managers in competing firms (Kock et al., 2003). This relationship becomes an important network between the organization and the other hotels. The benefits that the organization gets from this relationship are a collaboration to share overflow customers, mitigation of competition to avoid price wars, and information exchange concerning the fluctuations and recent trends. In results, the information that the organization gets is also essential to create strategic possibilities with valuable insights among managers. With all those benefits, the organization can be able to survive in the tight hotel business competition.

Proposition 23: In order to achieve sustainability in hospitality business, organizations seek to create a long-lasting trustworthy relationship with competitors.
Further, the level of comfort at the workplace may be changed or ruined if one or more employees are replaced by other persons. The level of comfort at this moment is highly achieved because of the employees as they create the comfort by themselves internally, so that such comfort will not be found exactly the same as the comfort now if the other persons are there replacing the employees now. This kind of workplace will stay the same if the employees are also the same. This is in line with the theory that successful teamwork relies upon synergism existing between all team members creating an environment where they are all willing to contribute and participate in order to promote and nurture a positive, effective team environment (Tarricone \& Luca, 2002). In the organization, there is a need of having a positive and effective team environment with a very good collaboration and social interdependence. It is also supported by the characteristics of the team which should be flexible enough to adapt in the environment.

Proposition 24: In order to achieve sustainability in hospitality business, organizations nurture a working environment that makes team members are all willing to contribute and participate in the working processes.

\section{Conclusion and Implication}

In conclusion, since the human assets of Dana Hotel are valuable, rare, imperfectly imitable, and non-substitutable, the status of Dana Hotel is sustainable. Following the success of Dana Hotel survives since 1953 in the tight hospitality business competitions in Solo using all twenty four factors above which are valuable, rare, imperfect imitable, and non-substitutable; a hotel that has those factors or even create more strategies tend to have big opportunities to be sustained in the context of human assets. As this is a working paper, the study is going to go further to the analysis of the physical and organizational assets of the hotel.

\section{References}

Akbar, S., Som, A. P., Wadood, F., \& Alzaidiyeen, N. J. (2010). Revitalization of service quality to gain customer satisfaction and loyalty. International Journal of Business and Management, 5 (6), 113-122.

Albert, E. (2010). Sustainable hotels, how the industry is moving beyond green. Retrieved February 1 , 2017, from https://www.oxy.edu/sites/default/ files/assets/UEP/Comps/2011/Erika\%20Albert_ Sustainable $\% 20$ Hotels $\% 20 \mathrm{How} \% 20^{\text {th }} \mathrm{e} \% 20 \mathrm{Indu}$ stry\%20is\%20Moving\%20Beyond\%20Green.p df. 
Barney, J. (1991). Firm resources and sustained competitive advantage. Journal of Management, $17,99-120$.

Budijanto, R. R. (2013). Thinking styles, teamwork quality, and performance. Doctoral dissertation, University of Canberra. Retrieved February 1, 2017, from http://www.canber ra.edu. au/research repository/file/cbf1815d-92bb-46a8-a7f7b3a55e 954f6b/1/full_text.pdf.

Buser, T. \& Peter, N. (2011). Multitasking: Productivity effects and gender differences. Retrieved February 1, 2017, from http://econ.core.hu/file/ download/korosi/2011/peter.pdf.

Glaser, B. G. \& Strauss, A. L. (1967). The discovery of grounded theory: Strategies for qualitative research. USA: Aldine Transaction: A Division of Transaction Publishers.

Golafshani, N. (2003). Understanding reliability and validity in qualitative research. The Qualitative Report, 8(4), 597-607.

Greenberg, E. S., Sikora, P. B., Grunberg, L., \& Moore, S. (2012). Work teams and organizational commitment: Exploring the influence of the team experience on employee attitudes. Retrieved February 1, 2017, from workplacechange: http://www.colorado.edu/ibs/PEC/workplacechang e/papers/WP_012.pdf.

Ingram, P. \& Roberts, P. W. (2000). Friendships among competitors in the Sydney hotel industry. American Journal of Sociology, 106(2), 387423.

Kock, S., Bengtsoon, M., \& Slotte-Kock, S. (2003). To compete or cooperate: A strategic dilemma. Retrieved February 1, 2017, from http://www. gsom.spbu.ru/files/upload/niim/seminar/strat egic_dilemma.pdf.
Noffytasari, P. (2010). The activities of public relations in Sahid Jaya Hotel Surakarta. Thesis, Sebelas Maret University. Retrieved February 1, 2017, from http://core.ac.uk/download/pdf/1234 7819.pdf.

PHRI. (2015). Kajian pengunjung di obyek dan atraksi wisata di kota Surakarta.

Rowley, J. (2002). Using case studies in research. Management Research News, 25(1), 16-27.

Rumambi, L. J. \& Djati, S. P. (2007). Hotel management and brand achievement: A study of hotel industry, 6, 45-54. Retrieved February 1, 2017, from http://fportfolio.petra.ac.id/user_files/91023/Hotel-Brand\%20Management.pdf.

Shamsuzzoha, A. \& Shumon, R. H. (2007). Employee turn over a study of its causes and effects to different industries in Bangladesh. Manufacturing Engineering/Vyrobne Inzinierstvo, 6(3), 6468.

Tarricone, P. \& Luca, J. (2002). Successful teamwork: A case study. Quality Conversations, Proceedings of the 25th HERDSA Annual Conference, Perth, Western Australia, 7-10 July 2002, pp. 640-646.

Uzzi, B. (1997). Social structure and competition in inter firm networks: The paradox of embeddedness. Administrative Science Quarterly, 42, 3567. Retrieved February 1, 2017, http://dx.doi. org/10.2307/2393808.

Zamzuri, N. H., Awang, K. W., \& Somdin, Z. (2011). Environmental issues in meeting, incentive, convention, and exhibition (MICE) tourism sector. The 2nd International Conference on Business, Economics and Tourism Management IPEDR, 24, 98-101. 